\title{
Electron-beam processing of the hardened layer formed on Hardox 450 steel electric-wire welding system Fe-C-V-Cr-Nb-W
}

\author{
S.V. Konovalov ${ }^{1,2, \dagger}$, V.E. Kormyshev ${ }^{1}$, Yu.F. Ivanov ${ }^{3,4}$, A.D. Teresov ${ }^{3}$ \\ †konovserg@gmail.com

\begin{abstract}
${ }^{1}$ Siberian State Industrial University, Kirov str., 42, 654007, Novokuznetsk, Russia ${ }^{2}$ Samara National Research University, Moskovskoye Shosse, 34, 443086, Samara, Russia
\end{abstract} \\ ${ }^{3}$ Institute of High Current Electronics SB RAS, pr. Academic, 2/3 6342021, Tomsk, Russia \\ ${ }^{4}$ National Research Tomsk Polytechnic University, Lenina av., 30, 634050, Tomsk, Russia
}

Combined surface treatment of steel Hardox 450 is reported, which includes depositing a layer with Fe, C, V, Cr, $\mathrm{Nb}, \mathrm{W}$ containing flux-cored wire by electro-contact method and its further irradiation by high-intensity pulsed electron beam. Tribological tests of the modified surface have been carried out and revealed the increase in wear resistance of the irradiated layer by 32.5 times as compared with the base material. The content of elements and the composition of phases, as well as the defect substructure of steel Hardox 450 and the deposited surface layer modified by high-intensity pulsed electron beam, have been explored by transmission and scanning electron microscopy. It has been indicated that a multilayer structure is formed due to electron-beam treatment of the deposited layer surface. The fact that interfaces of detected layers contain micropores and micro-cracks indicates their high-level consistency. A multiphase structure comprising $\alpha$-phase and niobium-, chromium- and iron based carbide phases has been detected in the layer modified by the electron beam. With the help of electron beam treatment of the deposited layer surface it is possible to decrease significantly the sizes of inclusions located both in the modified layer and in the bulk of deposited metal. The average size of inclusions before exposure to electron beam irradiation is $2.5 \mu \mathrm{m}$, whereas those in the irradiated samples are $0.6 \mu \mathrm{m}$. The layer of deposited metal irradiated by the intense pulsed electron beam is in elastically-stressed state, as shown by numerous extinction bend contours in carbide phase. Highspeed hardening of the deposited layer in the process of its pulsed electron beam irradiation leads to formation of massive martensite with ultra small cross sectional $(40-70 \mathrm{~nm})$ dimensions of martensite crystals.

Keywords: structure, wear resistance, steel Hardox 450, flux-cored wire, electric welding, electron beam treatment.

\section{Электронно-пучковая модификация упрочненного слоя, сформированного на стали Наrdox 450 электроконтактной наплавкой проволоки системы Fe-C-V-Cr-Nb-W}

\footnotetext{
Коновалов С.В. ${ }^{1,2 \dagger}$, Кормышев В.Е. ${ }^{1}$, Иванов Ю.Ф. ${ }^{3,4}$, Тересов А.Д. ${ }^{3}$

${ }^{1}$ Сибирский государственный индустриальный университет, ул. Кирова, 42, 654007, Новокузнецк, Россия ${ }^{2}$ Самарский национальный исследовательский университет имени академика С.П. Королева, ул. Московское шоссе, д.34, 443086, Самара, Россия

${ }^{3}$ Институт сильноточной электроники СО РАН, пр. Академический, 2/3, 6342021, Томск, Россия

${ }^{4}$ Национальный исследовательский Томский политехнический университет, пр. Ленина, 30, 634050, Томск, Россия

Осуществлена комбинированная обработка поверхности стали Hardox 450, заключающаяся в формировании электроконтактным методом слоя, наплавленного порошковой проволокой состава $\mathrm{Fe}-\mathrm{C}-\mathrm{V}-\mathrm{Cr}-\mathrm{Nb}-\mathrm{W}$, и его последующем облучении высокоинтенсивным импульсным электронным пучком. Выполнены трибологические испытания модифицированной поверхности и выявлено увеличение в 32,5 раза износостойкости облученного слоя по сравнению с материалом основы. Методами просвечивающей и сканирующей электронной микроскопии осуществлены исследования элементного и фазового состава, дефектной субструктуры стали Hardox 450 и поверхностного слоя наплавки, модифицированной высокоинтенсивным импульсным электронным пучком. Показано, что электроннопучковая обработка поверхности наплавленного слоя сопровождается формированием многослойной структуры. Границы раздела выявленных слоев не содержат микропор и микротрещин, что свидетельствует о высоком уровне их совместности. Выявлено формирование в модифицированном электронным пучком слое многофазной структуры, представленной а-фазой и карбидными фазами на основе ниобия, хрома и железа. Электронно-пучковая обра-
} 
ботка поверхности наплавленного слоя приводит к многократному уменьшению размеров включений, расположенных как в модифицированном слое, так и в основном объеме наплавленного металла. До облучения электронным пучком средние размеры включений 2,5 мкм, после облучения - 0,6 мкм. Слой наплавленного металла, подвергнутый облучению интенсивным импульсным электронным пучком, находится в упруго-напряженном состоянии, о чем свидетельствует наличие многочисленных изгибных экстинкционных контуров, присутствующих в выделениях карбидной фазы. Показано, что высокоскоростная закалка наплавленного слоя, реализующаяся при его облучении импульсным электронным пучком, сопровождается формированием пакетного мартенсита с ультрамалыми поперечными (40 - 70 нм) размерами кристаллов мартенсита.

Ключевые слова: структура, износостойкость, сталь Hardox 450, порошковая проволока, электроконтактная наплавка, электронно-пучковая обработка.

\section{1. Введение}

Детали машин и механизмов многих отраслей промышленности (металлургических заводов, горнодобывающих, нефтедобывающих, дорожно-ремонтных и многих других предприятий) работают в условиях интенсивного износа, защита от которого весьма часто осуществляется нанесением покрытий, выполняемым лазерным, плазменным, электронно-лучевым, электродуговым и др. методами [1]. Основным ограничением к широкому использованию данного метода является недостаточно высокий уровень адгезии покрытия к подложке. Весьма перспективным в настоящее время является метод электроконтактной наплавки, заключающийся в формировании на рабочей поверхности детали или изделия наплавленного слоя (металлы и сплавы, металлокерамические и керамические материалы), обладающего повышенными эксплуатационными характеристиками $[2,3]$. Наплавка является малозатратным, но при этом высокоэффективным методом ремонта и защиты изделий. В ряде работ $[4,5]$ на примере покрытия, сформированного электровзрывным методом на поверхности сплавов на основе железа и титана, было показано, что дополнительное облучение поверхности сформированного слоя высокоинтенсивным импульсным пучком электронов способствует кратному повышению трибологических свойств материала.

Целью настоящей работы являлся анализ результатов, полученных при исследовании структуры и износостойкости слоя, сформированного на стали Hardox 450 электроконтактной наплавкой проволоки системы $\mathrm{Fe}-\mathrm{C}-\mathrm{V}$ - Cr-Nb-W, дополнительно облученного высокоинтенсивным импульсным электронным пучком.

\section{2. Материалы и методики}

В качестве материала основы, как и в [6], использовали сталь марки Hardox 450 ((вес. \%): 0,19-0,26 C; 0,70 Si; 1,6 Mn; 0,025 P; 0,010 S; 0,25 Cr; 0,25 Ni; 0,25 Mo, 0,004 B; остальное - Fe). Наплавку осуществляли порошковой проволокой ПП-2 следующего химического состава (вес. \%): 1,4 C; 1,0 V; 7,0 Cr; 8,0 Nb; 1,2 W; остальное - Fe. Наплавку методом MIG/MAG (MIG/MAG - Metal Inert Gas/Metal Active Gas - дуговая сварка плавящимся металлическим электродом (проволокой) [7] в среде инертного/активного газа с автоматической подачей присадочной проволоки) проводили в среде защитного газа $\left(\mathrm{Ar}-82 \%, \mathrm{CO}_{2}-18 \%\right)$ при сварочном токе 250 - 300 А и напряжении 30 - 35 В.
Модифицирование наплавленного слоя осуществляли, облучая поверхность высокоинтенсивным импульсным электронным пучком на установке СОЛО [8-10] в режиме плавления и высокоскоростной кристаллизации в два этапа: параметры пучка электронов на первом этапе - плотность энергии пучка электронов в импульcе $E_{S}=30$ Дж $/ \mathrm{cm}^{2}$; длительность импульсов $\tau=200$ мкс; количество импульсов $N=20$; на втором этапе

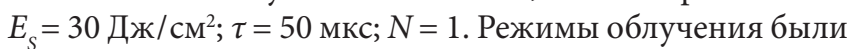
выбраны исходя из результатов расчета температурного поля, формирующегося в поверхностном слое материала при облучении в одноимпульсном режиме. Трибологические испытания модифицированной поверхности осуществляли на трибометре «CSEM Tribometer High Temperature S/N 07-142», CSEM Instruments; контртело - шарик диаметром 2 мм из твердого сплава ВК6, скорость износа оценивали по площади поперечного сечения трека износа, используя 3D-профилометр MICRO MEASURE 3D station фирмы STIL. Структуру объема модифицированного слоя анализировали методом поперечного шлифа, для чего образцы разрезали на две части перпендикулярно поверхности модифицирования. Дефектную структуру материала изучали методами оптической (микроскоп «Микровизор металлографический $\mu$ Vizo - MET-221»), сканирующей (сканирующий электронный микроскоп «SEM-515 Philips») и просвечивающей дифракционной (приборы ЭМ-125 и FEI Tecnai G220 TWIN) электронной микроскопии. Элементный состав поверхностного слоя определяли методами микрорентгеноспектрального анализа (микроанализатор EDAX ECON IV, являющийся приставкой к электронному сканирующему микроскопу SEM-515 «Philips»).

\section{3. Результаты и обсуждение}

Исследования свойств поверхности наплавленного слоя, дополнительно облученного интенсивным импульсным электронным пучком, выявили (относительно подложки, сталь марки Hardox 450) увеличение износостойкости в $\approx 32,5$ раза и коэффициента трения в $\approx 1,1$ раза. Очевидно, что кратное увеличение износостойкости модифицированного слоя обусловлено существенным преобразованием фазового состава и дефектной субструктуры материала. Рассмотрим этот вопрос подробнее.

Методами сканирующей электронной микроскопии травленного поперечного шлифа установлено, что облучение наплавленного материала интенсивным импульсным электронным пучком приводит к формированию 
многослойной структуры, характерное изображение которой приведено на рис. 1. По морфологическому признаку выявляются сравнительно тонкий (2-3 мкм) поверхностный слой (рис. 1, слой 1), переходный слой, толщина которого (40-45 мкм) (рис. 1, слой 2), переходящий в основной объем наплавленного металла (рис. 1, слой 3). Следует отметить, что границы раздела выявленных слоев не содержат микропор и микротрещин, что свидетельствует о высоком уровне их совместности.

Травление структуры наплавленного слоя ионным пучком позволило выявить тугоплавкие (плохо распыляемые ионным пучком) включения, расположенные как в модифицированном слое, так и в основном объеме наплавленного металла. Электронно-пучковая обработка поверхности наплавленного слоя приводит к многократному уменьшению размеров этих включений (рис. 1). До облучения электронным пучком средние размеры включений 2,5 мкм, после облучения - 0,6 мкм.

Методами сканирующей электронной микроскопии был осуществлен микрорентгеноспектральный анализ элементного состава поверхностного слоя, модифицированного интенсивным импульсным электронным пучком (рис. 2). В результате выполненных исследований установлено, что основными карбидообразующими легирующими элементами поверхностного слоя следует считать хром, ниобий и железо, в меньшей степени, титан и ванадий, концентрация которых сравнительно низка (рис. 2, таблица). Таким образом, следует ожидать, что тугоплавкие включения, выявленные при исследовании методами сканирующей электронной микроскопии поперечного травленого шлифа (рис. 1) являются частицами карбидной фазы.

Фазовый состав и дефектную субструктуру стали Hardox 450, а также наплавленного слоя после облучения высокоинтенсивным импульсным электронным пучком анализировали методами просвечивающей электронной дифракционной микроскопии тонких фольг. В результате выполненных таким образом исследований выявлено, что сталь Hardox 450 следует отнести к многофазным материалам, основными фазами которого являются $\alpha$-фаза и карбид железа. $\alpha$-фаза представлена двумя морфологически различными типами структуры, а именно, мартенситом пакетной морфологии (рис. 3а) и субзернами (рис. 3b). Основным морфологическим типом структуры стали является пакетный мартенсит, поперечные размеры кристаллов которого изменяются в пределах 150-200 нм. В объеме и на границах кристаллов мартенсита, а также субзерен $\alpha$-фазы располагаются частицы второй фазы. Индицирование микроэлектронограмм, полученных с таких участков материала, показало, что данные частицы являются карбидом железа состава $\mathrm{Fe}_{3} \mathrm{C}$. Исходя из морфологии структуры $\alpha$-фазы и фазового состава, можно заключить, что сталь Hardox 450 перед формированием наплавленного слоя была подвергнута закалке (сформировался пакетный мартенсит) и последующему отпуску (сформировались частицы карбида железа и области с субзеренной структурой).

Характерное изображение структуры наплавленного слоя, подвергнутого дополнительному облучению высокоинтенсивным импульсным электронным пучком, представлено на рис. 4.

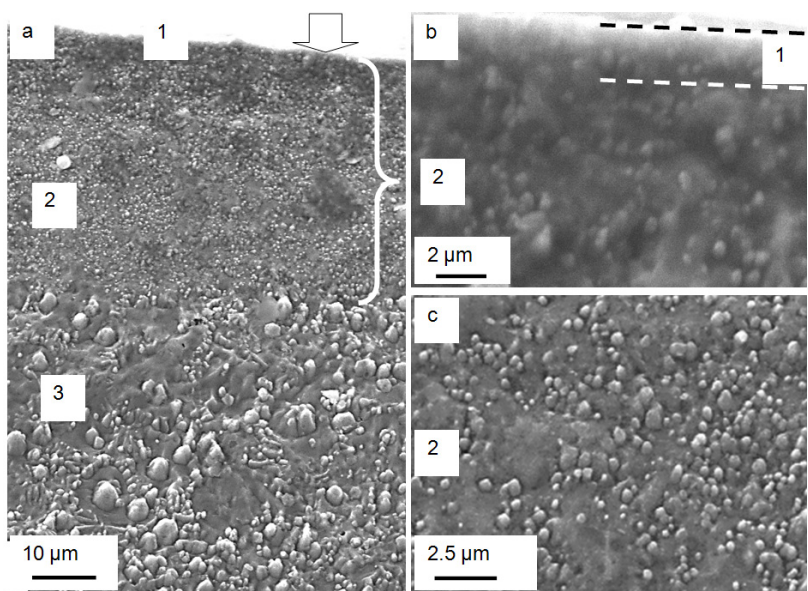

Рис. 1. Структура поперечного сечения наплавленного на сталь марки Hardox 450 слоя, подвергнутого облучению интенсивным импульсным электронным пучком; на (а) обозначено: 1 поверхностный слой; $2-$ переходный слой; $3-$ основной объем наплавленного металла; фигурной скобкой выделен слой, модифицированный интенсивным импульсным электронным пучком; (b) - увеличенное изображение структуры слоя 1; (c) - увеличенное изображение структуры слоя 2.

Fig. 1. Cross-section structure of the layer deposited on steel Hardox 450 and exposed to intense pulsed electron beam irradiation; in (a): 1 - surface layer; 2 - transition layer; 3 - bulk of the deposited metal; the layer modified by intense pulsed electron beam is in curly brackets; (b) - magnified image of layer 1 structure; (c) magnified image of layer 2 structure.

\begin{tabular}{|c|c|}
\hline $\begin{array}{l}\text { Элемент } \\
\text { Element }\end{array}$ & $\begin{array}{l}\text { Beсовой \% } \\
\text { Weight \% }\end{array}$ \\
\hline $\mathrm{C} \mathrm{K}$ & 0.90 \\
\hline $\mathrm{Si} \mathrm{K}$ & 0.7 \\
\hline $\mathrm{Ti} \mathrm{K}$ & 0.2 \\
\hline $\mathrm{V} \mathrm{K}$ & 0.6 \\
\hline $\mathrm{Cr} \mathrm{K}$ & 5.2 \\
\hline $\mathrm{Fe} \mathrm{K}$ & 89.0 \\
\hline $\mathrm{Nb} \mathrm{L}$ & 3.4 \\
\hline
\end{tabular}
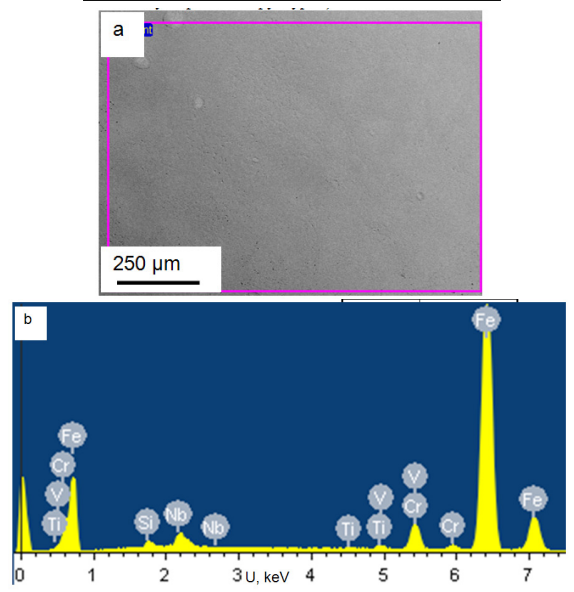

Рис. 2. Структура поверхности облучения интенсивным импульсным электронным пучком наплавленного на сталь марки Hardox 450 слоя (a); (b) - энергетические спектры, полученные с области, выделенной на (а) прямоугольником; в таблице указан относительный элементный состав анализируемого участка наплавки (a).

Fig. 2. Surface structure of the layer deposited on steel Hardox 450 and exposed to intense pulsed electron beam irradiation (a); (b) energy spectra obtained using the area highlighted in rectangle (a); Table provides the relative content of elements in the deposited layer to be analyzed (a). 
Индицирование микроэлектронограмм, полученных с наплавленного слоя, подвергнутого облучению высокоинтенсивным импульсным электронным пучком, выявило, наряду с рефлексами $\alpha$-фазы (твердый раствор на основе ОЦК кристаллической решетки железа) рефлексы карбида ниобия состава $\mathrm{Nb}_{2} \mathrm{C}$, карбида хрома состава $\mathrm{Cr}_{7} \mathrm{C}_{3}$ и сложного карбида на основе атомов хрома и железа состава $\mathrm{M}_{23} \mathrm{C}_{6}$ (пример приведен на рис. 4).

Высокоскоростная закалка, реализующаяся при облучении наплавленного слоя интенсивным импульсным электронным пучком, приводит к формированию в поверхностном слое мартенситной структуры $\alpha$-фазы, характерное изображение которой приведено на рис. 5. Мартенсит по морфологическому признаку является пакетным (реечным). Поперечные размеры кристаллом пакетного мартенсита изменяются в пределах 40-70 нм (рис. 5). Напомним, что закалка стали Hardox 450 с печного нагрева привела к формированию пакетного мартенсита, средние поперечные размеры которых составляют 150 - 200 нм. Следовательно, скоростная закалка наплавленного слоя, реализующаяся при облучении материала интенсивным импульсным электронным пучком, приводит к многократному измельчению структуры пакетного мартенсита поверхностного слоя. Следует отметить, что слой наплавленного металла, подвергнутый облучению интенсивным импульсным электронным пучком, находится в упруго-напряженном состоянии, о чем свидетельствуют многочисленные изгибные экстинкционные контуры, присутствующие в выделениях карбидной фазы (рис. 5, контуры указаны стрелками). Как правило, контуры начинаются и оканчиваются на межфазных границах карбид/ $\alpha$-фаза, что указывает на механизм формирования кривизны-кручения кристаллической решетки материала - упругие поля напряжений термического происхождения, формирующиеся в результате несоответствия коэффициентов термического расширения карбидной фазы и $\alpha$-фазы.

Таким образом, формирование на поверхности стали Hardox 450 наплавленного слоя и последующее облучение его интенсивным импульсным электронным пучком приводит к формированию модифицированного поверхностного слоя толщиной до 50 мкм, имеющего многофазную структуру, представленную карбидами

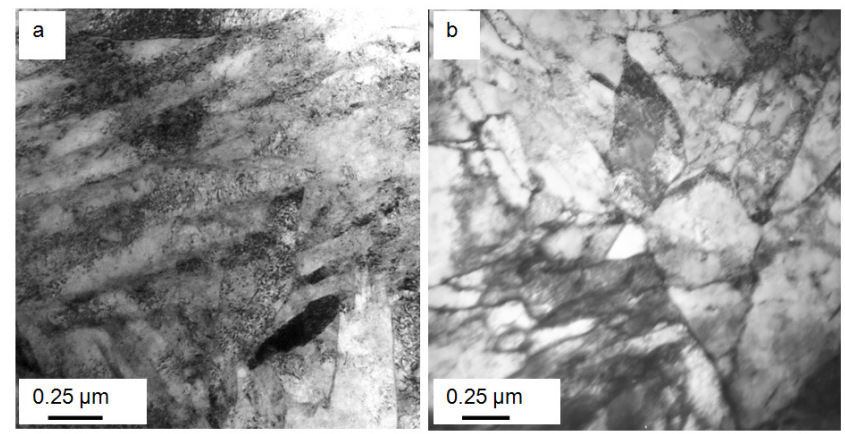

Рис. 3. Электронно-микроскопическое изображение структуры стали Hardox 450; (a) - мартенсит пакетной морфологии; (b) - субзерна $\alpha$-фазы.

Fig. 3. Electron microscope image of steel Hardox 450 structure; (a) - morphology of batch martensite; (b) $-\alpha$-phase sub-grains. легирующих элементов, расположенными в $\alpha$-фазе, закаленной на мартенсит пакетной морфологии, поперечные размеры кристаллом которого многократно меньше поперечных размеров кристаллов стали, закаленной после печного нагрева.

\section{4. Заключение}

Показано, что облучение высокоинтенсивным импульсным электронным пучком упрочненного слоя, сформированного на стали Hardox 450 электроконтактной наплавкой проволоки системы Fe-C-V-Cr-Nb-W coпровождается многократным увеличением износостойкости (в 32,5 раз) наплавленного слоя. Установлено, что повышение трибологических свойств модифицированного электронным пучком наплавленного слоя обусловлено формированием многослойной структуры, упрочнение которой вызвано эффектом высокоскоростной закалки, сопровождающейся образованием
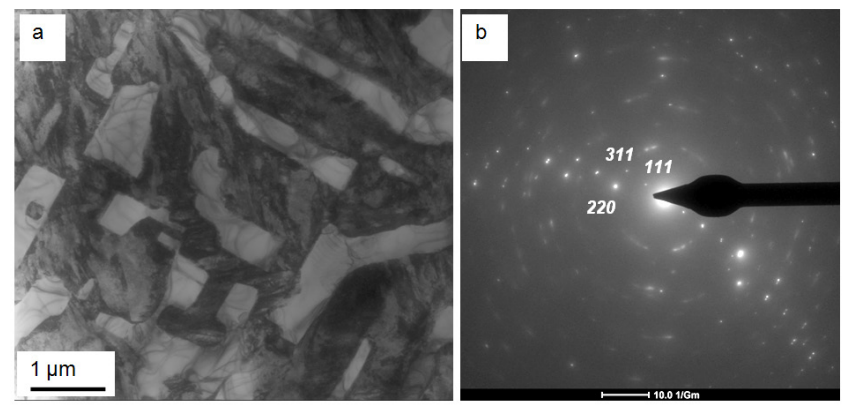

Pис. 4. Электронно-микроскопическое изображение (а) и микроэлектронограмма (b) данного участка фольги, изготовленной путем ионного утонения пластинки, вырезанной из слоя наплавленного металла, облученного высокоинтенсивным импульсным электронным пучком; на (b) указаны индексы плоскости [112] карбида $\mathrm{M}_{23} \mathrm{C}_{6}$.

Fig. 4. Electron microscopic image (a) and micro-electron diffraction pattern (b) of the foil sample produced by ion thinning a plate cut out of the deposited metal layer irradiated by the high-intensity pulsed electron beam; (b) specifies $\mathrm{M}_{23} \mathrm{C}_{6}$ carbide plane indices [112].

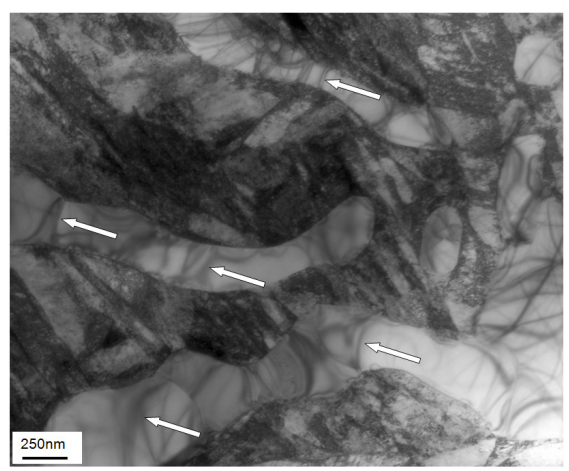

Рис. 5. Структура поверхностного слоя наплавки, модифицированной в результате облучения интенсивным импульсным электронным пучком; стрелками указаны изгибные экстинкционные контуры, расположенные в частицах карбидной фазы.

Fig.5. Structure of the deposited surface layer modified in the process of intense pulsed electron beam irradiation; the arrows indicate the extinction bend contours, located in carbide phase particles. 
мартенсита пакетной морфологии, поперечные размеры кристаллом которого в (3-4) раза меньше поперечных размеров кристаллов стали, закаленной после печного нагрева, и наличием включений карбидной фазы (карбида ниобия состава $\mathrm{Nb}_{2} \mathrm{C}$, карбида хрома состава $\mathrm{Cr}_{7} \mathrm{C}_{3}$ и сложного карбида на основе атомов хрома и железа состава $\mathrm{M}_{23} \mathrm{C}_{6}$ ).

Благодарность/Acknowledgements. Исследование вьполнено за счет гранта Российского научного фонда (проект № 15-19-00065).

\section{Литература/References}

1. М. Хокинг, В. Васантасри, П. Сидки. Металлические и керамические покрытия. Получение, свойства и применение: Пер. с англ. - М.: Мир, 2000. — 518 с.

2. V.I. Chernoivanov, I.G. Golubev. Restoration of machine parts (Status and Prospects). Moscow, FGNU «Rosinformagroteh». (2010) 376 p. (in Russian) [В.И. Черноиванов, И.Г. Голубев И.Г. Восстановлен ие деталей машин (Состояние и перспективы). М.: ФГНУ «Росинформагротех». 2010. 376 с]

3. Y. Zhirkin. Reliability, maintenance and repair of metallurgical machinery. Magnitogorsk, NSTU. (2002) 330 p. (in Russian) [Ю.В. Жиркин. Надежность, эксплуатация и ремонт металлургических машин. Магнитогорск, НГТУ. 2002. 330 c]

4. А.М. Глезер, В.Е. Громов, Ю.Ф. Иванов, Ю.П. Шаркеев. Наноматериалы: структура, свой- ства, применение. - Новокузнецк: Изд-во «ИнтерКузбасс», 2012. - 428 с.

5. Структура, фазовый состав и свойства поверхностных слоев титана после электровзрывного легирования и электронно-пучковой обработки/Под ред. В.Е. Громова, Ю.Ф. Иванова, Е.А. Будовских. Новокузнецк: Изд-во «Интер-Кузбасс», 2012. - 435 с.

6. S. Konovalov, V. Kormyshev, V. Gromov, Yu. Ivanov. Materials Science Forum. 870, 159-162 (2016), Doi:10.4028/www.scientific.net/MSF.870.159.

7. В.М. Малыш, М.М. Сорока. Электрическая сварка. - Киев: Техніка, 1986.

8. Yu. F. Ivanov, N.N. Koval. Low-energy electron beams submillisekundnoy duration: reception and some aspects of the application in the field of materials science Chapter 13 in the book «Structure and properties of advanced metallic materials.» p. 345-382/Ed.A. I. Potekaev. Tomsk: Publishing house of the NTL. (2007) 580 р. (in Russian) [Иванов Ю. Ф., Коваль Н. Н. Низко энергетические электронные пучки субмиллисекундной длительности: получение и некоторые аспекты применения в области материаловедения - Гл.13 в книге «Структура и свойства перспективных металлических материалов». - С.345-382/Под общ. ред. А. И. Потекаева. Томск. НТЛ. 2007.580 с.]

9. V.A. Grishunin, V. E. Gromov, Y.F. Ivanov, A. D. Teresov, S. V. Konovalov. Journal of Surface Investigation 7 (5), 990 - 995 (2013), Doi: 10.1134/S1027451013050091

10. N. N. Koval', Yu. F. Ivanov. Russian Physics Journal 51 (5), 505 - 516 (2008), Doi: 10.1007/s11182-008-9073 -7 